\title{
Application Research of Library Management System of Network and Information Technology
}

\author{
Junxia Qi \\ Library, Handan College,Handan,056005,China \\ junxiaqi@yeah.net
}

Keywords: Library; System model; Data mining

\begin{abstract}
The school library is one of organic component in the school organization system, which is an important place for the teachers and the students to learn in, improve the quality of education and train talents. With the deepening of the curriculum reform, schools are in the development towards characteristics and diversification, and the requirements to the students of personalized development are more and more. It requires educational and teaching resources including libraries to serve the needs of this transformation. This article focuses on the design of the library management system model of the middle schools, and it achieves personalized books recommendation combined with the data mining technology
\end{abstract}

\section{Foreword}

The library is the distributing center of human civilization and the links of literature information resource communication. The school library is one of organic component in the school organization system, which is an important place for the teachers and the students to learn in, to improve the quality of education and to train talents. Many countries in the world attach great importance to the construction of the school library.

However, there are a lot of school libraries, especially the libraries in the middle school, failed to go with the current of times to conduct reforming. They still use the traditional methods for management and service. At present, although the scientific and standardized library book catalog classification methods are used and the library resources are managed by means of computer and database, teachers and students need to spend more time to search for their needs and the literature resources with better quality based on the rapid popularization of information technology with increasing of total amount of resources.

The system database technology and the database management system are increasingly widely used in various industries, more and more data is accumulated and even the emergence of "data explosion" phenomenon. According to the relevant statistics, the amount of global information will be doubled every 20 months. How to process these data? It is apparent that they have no interesting to enjoy it but feel it is pity to throw it away. The question of how make these data do not become a burden and it is conducive to our work, life and learning has been pondering by many people. For this, the data mining technology is introduced --- it is a process to extract the potentially useful information and knowledge, which is implied, included and unknown by people in advance, from mass, incomplete, noisy, fuzzy and random practical application data. In the research of database and information decision, data mining technology has become one of the international advanced research fields so that uncertainty and risk are effectively reduced and it provides the basis for human decision making [2].

Computer network technology and database technology provide hardware and software infrastructure and technical support for the informatization of operation and management of library information. However, the emergence of data mining technology makes the personalized library services become possible. Foreign countries have begun to innovate management and service model of library by using data mining technology. American government began to construct the digital 
library [3] in 1990. The concept of personalized information service was put forward by the 10 famous experts from American library and Information Technology Association (LITA) in 1999. Besides the passive service, the library shall provide the active service either. Members of many American university librarians carried out many practical applications together with some backbone of computer specialized major. America Cornell University (The Cornell University) library developed the Mylibrary@cornell system. When the system detects information changing of books which are interested in by the teachers and the students, it will inform the user [5] actively. Japan Hiroshima University library developed personalized information environment (A Personalized Information Environment) [4] system to mining and establishing the interest degree model of users according to the historical data of database and it can calculate the relevant weight according to their own characteristics of the teachers and the students. The system will recommend relevant information to users through the calculation of model.

Domestic libraries are still in their initial stage for the application of data mining technology and research. The data volume is greatly enlarged [6] since the introduction of automated library management system based on database. The traditional database technology can only statistic and search for the massive data. It is difficult to find the intrinsic and deep-seated problems.

\section{System Functions Analysis and General Framework}

System Functions Analysis: Under the current circumstances, books borrowing are still the most important needs of students and teachers for many services in the library. However, the requirements for convenience of books searching and borrowing have been greatly improved. For the management personnel, the "intelligent" level of the books management system shall be improved. The system shall be able to take the initiative to identify problems and notify the management personnel. Therefore, it is necessary to re-design the library management system. It is not difficult for us to find out the problems and requirements for the library management system in the current middle school. Accordingly, the following functional requirements can be put forward:

$\mathrm{B} / \mathrm{S}$ structure is applied; you can fast visit the school library management system in the school;

Provide the convenient functions as books searching, borrowing and renewal;

Breakthrough in personalized services, such as books recommendation etc;

Some rules of books borrowing data could be discovered and it helps the management personnel to carry out the analysis and decision-making.

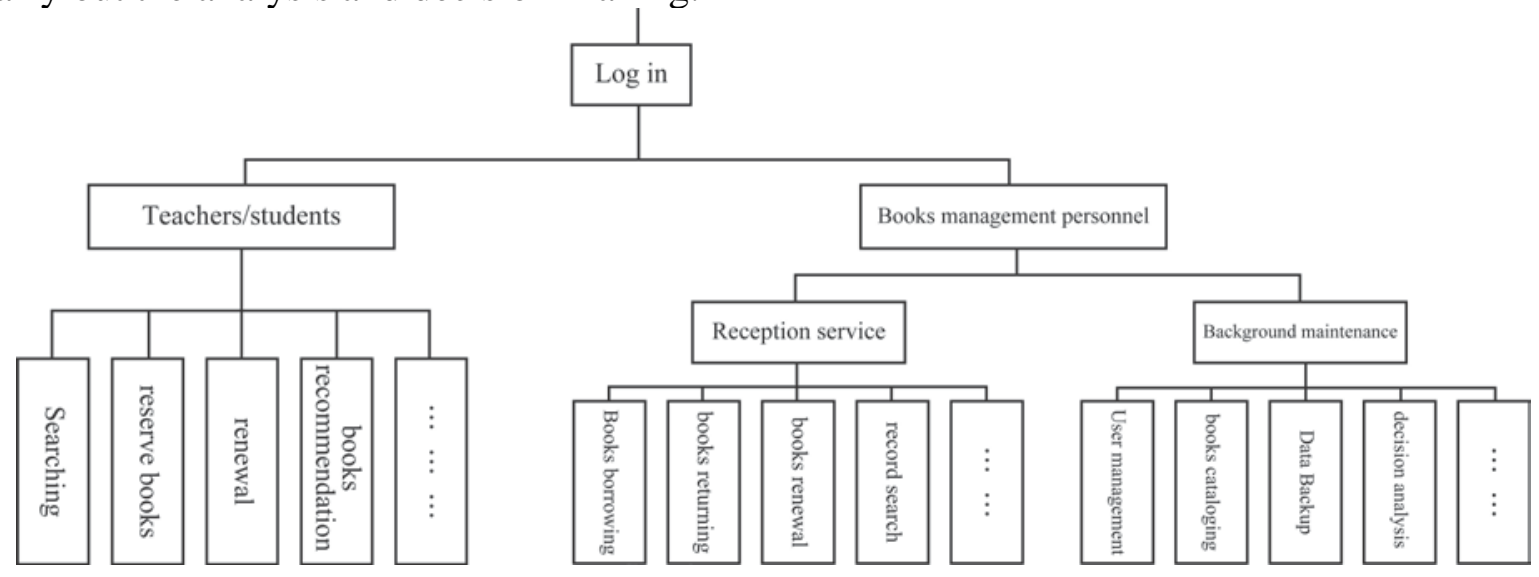

Figure I Module Chart of System Function

System Design: The books management system is not simple from the structure due to application of the database, data warehouse and data mining technology. The following are comprising of system logic structure, hierarchical structure and network structure, respectively [8]:

System Logic Structure 


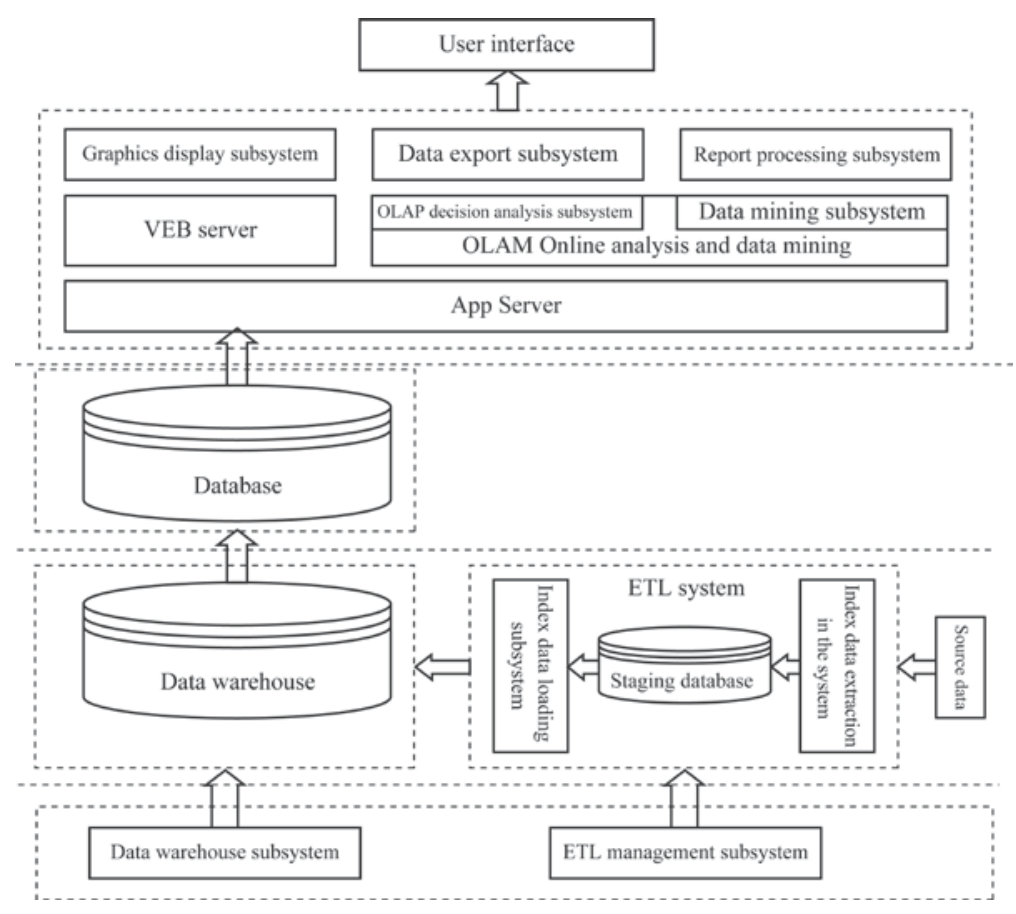

Figure2 System Logic Chart

System Hierarchical Structure Chart

Library management system can be divided into 5 levels based on the hierarchical structure as application, security service, WEB service, and business logic and data storage.

Data storage level: The data, which is standardized in the database, will be restored in the database.

Business logic level: a connecting link between the preceding and the following, the data and application is relatively independent and the system scalability and portability is improved.

WEB service level: provide various types of service for users in the form of Web-page.

Security service level: protect the system and ensure the security of data in data warehouse.

Application level: provide the uniform interface and easy operation interface for users.

Network Topology Structure: The following points could be listed from the existing hardware conditions and application requirements:

Good internal network equipment and campus network access conditions.

The data and information in data warehouse could be shared in the system to the utmost extent and be released to the teachers and the students according to the different levels.

Prevent hacker attacks, virus transmission data destructive behavior as far as possible in the network layout design.

Ordinary teachers and students can search the literature information in the system in office and classroom and reserve borrowing and renewal are permissible.

\section{Data Mining System}

After clustering analysis according to the times of book borrowing by clustering techniques, the book borrowing behaviors of students in each class have certain similarity and further study could be performed. However, for students in the same class only have some similarities on times of borrowing, there also have big differences on kinds of book borrowing. If it is deeply subdivided by borrowing books category, it is conducive to books recommendation. Even if the size of the school library where the author located is small, the classification of the books is strictly according to the CLC classification from A- Marxism Leninism, Mao Zedong thought and Deng Xiaoping theory to Z- general books were given the classification number and each kind of book is given to the class II classification. However, class I classification is used to facilitate the study due to the borrowing amount of students is relatively insufficient. Personalized books recommendation as per individual characteristics of students must be based on the automated library management system. The existing 
technology is used to achieve the most simple of data mining. The issue of how to use data mining technology to analyze the students and the borrowing records has been discussed in this paper. On this basis, we can be more convenient to carry out data mining. ST1 book recommendation process for students is as follows:

Step 1, identify the clustering identification of students ST1in the database where the clustering analysis results of students are stored.

Step 2, carry out clustering analysis for books category which is borrowed recently by student ST1 $\mathrm{n}(\mathrm{n}<=10)$ and combination of books borrowing category by students with the same cluster labeling and find out the students with minimal differences on interest in reading.

Step 3, mining the borrowing books category of students with similar interest in reading books including students ST1 by association rules data and finding out books classification with the highest correlation degree.

ts who has the similar interest in reading with student ST1 in the library borrowing records, and then select the borrowing records of books interested by them, carry out data cleaning of selected borrowing records to remove some irrelevant information and only keep the student number, book number to form students-books two-dimensional table.

Step 5, carry out data mining for the books in the students-books two-dimensional table by the correlation rules and analyze the several books with the highest correlation degree. If student ST1 borrowed the books with the highest correlation degree, the books in the correlation rules are recommended to him.

Step 6, Transposing the students - books two dimensional table to form books - students twodimensional table and mining books classification with similar readership for data of books borrowers by means of clustering analysis. If student ST1 browsed or borrowed the book in the classification, all the books in the classification shall be recommended to student ST1. If ST1 does not browse or borrow any books in the classification, the first few books in the books classification which is closed to readers shall be recommended to student ST1 after clustering analysis. Through the above six steps, the books which are most likely to be borrowed by student ST1 and the books are recommended to him for reference.

Recommend the books with the highest correlation degree to them from the books classification which is interested by students. The system, however, could only recommend the other several books which borrowed or browsed by students to him. If he does not borrow or browse through any of these books, how to recommend? You can transpose the table to form books - students' twodimensional table. To facilitate the mining, firstly, statistic the borrowed books and then select $\mathrm{n}$ (10) books with maximum borrowing times. Carry out clustering analysis for the above-mentioned data and make classification for the difference value of students who borrow books. Calculate the results of difference for the books borrower.

Table 1, Books - Students Two-dimensional Table

\begin{tabular}{|c|c|c|c|c|c|c|c|c|}
\hline Txm & \multicolumn{7}{|c|}{ Stu } & \\
\hline $\mathrm{B}_{1}(29208)$ & $\mathrm{X}_{1}$ & $\mathrm{X}_{4}$ & $\mathrm{X}_{8}$ & $\mathrm{X}_{10}$ & & & & \\
\hline $\mathrm{B}_{2}(29209)$ & $\mathrm{X}_{1}$ & $\mathrm{X}_{5}$ & $\mathrm{X}_{7}$ & & & & & \\
\hline $\mathrm{B}_{3}(29214)$ & $\mathrm{X}_{1}$ & $\mathrm{X}_{4}$ & $\mathrm{X}_{6}$ & $\mathrm{X}_{8}$ & $\mathrm{X}_{9}$ & $\mathrm{X}_{10}$ & & \\
\hline $\mathrm{B}_{4}(29288)$ & $\mathrm{X}_{1}$ & $\mathrm{X}_{4}$ & $\mathrm{X}_{6}$ & $\mathrm{X}_{8}$ & $\mathrm{X}_{10}$ & & & \\
\hline $\mathrm{B}_{5}(29248)$ & $\mathrm{X}_{2}$ & $\mathrm{X}_{3}$ & $\mathrm{X}_{5}$ & $\mathrm{X}_{7}$ & $\mathrm{X}_{8}$ & $\mathrm{X}_{9}$ & & \\
\hline $\mathrm{B}_{6}(29299)$ & $\mathrm{X}_{1}$ & $\mathrm{X}_{4}$ & $\mathrm{X}_{6}$ & $\mathrm{X}_{9}$ & $\mathrm{X}_{10}$ & & & \\
\hline $\mathrm{B}_{7}(29278)$ & $\mathrm{X}_{2}$ & $\mathrm{X}_{4}$ & $\mathrm{X}_{8}$ & & & & & \\
\hline $\mathrm{B}_{8}(30078)$ & $\mathrm{X}_{1}$ & $\mathrm{X}_{3}$ & $\mathrm{X}_{5}$ & $\mathrm{X}_{7}$ & $\mathrm{X}_{8}$ & $\mathrm{X}_{10}$ & & \\
\hline $\mathrm{B}_{9}(30086)$ & $\mathrm{X}_{1}$ & $\mathrm{X}_{2}$ & $\mathrm{X}_{3}$ & $\mathrm{X}_{7}$ & $\mathrm{X}_{9}$ & $\mathrm{X}_{10}$ & & \\
\hline
\end{tabular}




\begin{tabular}{|c|c|c|c|c|c|c|c|c|}
\hline $\mathrm{B}_{10}(30160)$ & $\mathrm{X}_{1}$ & $\mathrm{X}_{2}$ & $\mathrm{X}_{3}$ & $\mathrm{X}_{5}$ & $\mathrm{X}_{6}$ & $\mathrm{X}_{7}$ & $\mathrm{X}_{8}$ & $\mathrm{X}_{10}$ \\
\hline
\end{tabular}

Distance value of not more than 0.33 is taken as the judgment value of books that have similar readers. Find out the combination of readers with different value of less than 0.33 and finally, four books classification combination could be divided. Books in each books classification have the similar readers. If students browse or recently borrows one book $\mathrm{Bn}$ in these books, then he is likely to borrow the books as Bo Bm Bp in the books combination which is similar to $\mathrm{Bn}$ that has similar readers.

Table 2. Differential Value Table of Books Borrower

\begin{tabular}{|c|c|c|c|c|c|c|c|c|c|c|}
\hline $\mathrm{d}$ & $\mathrm{B}_{1}$ & $\mathrm{~B}_{2}$ & $\mathrm{~B}_{3}$ & $\mathrm{~B}_{4}$ & $\mathrm{~B}_{5}$ & $\mathrm{~B}_{6}$ & $\mathrm{~B}_{7}$ & $\mathrm{~B}_{8}$ & $\mathrm{~B}_{9}$ & $\mathrm{~B}_{10}$ \\
\hline $\mathrm{B}_{1}$ & 0 & & & & & & & & & \\
\hline $\mathrm{B}_{2}$ & 0.75 & 0 & & & & & & & & \\
\hline $\mathrm{B}_{3}$ & 0.33 & 0.5 & 0 & & & & & & & \\
\hline $\mathrm{B}_{4}$ & 0.2 & 0.8 & 0.17 & 0 & & & & & & \\
\hline $\mathrm{B}_{5}$ & 0.53 & 0.67 & 0.83 & 0.83 & 0 & & & & & \\
\hline $\mathrm{B}_{6}$ & 0.6 & 0.8 & 0.5 & 0.5 & 0.67 & 0 & & & & \\
\hline $\mathrm{B}_{7}$ & 0.25 & 0.67 & 0.5 & 0.4 & 0.8 & 0.8 & 0 & & & \\
\hline $\mathrm{B}_{8}$ & 0.96 & 0.67 & 0.67 & 0.67 & 0.67 & 0.83 & 0.67 & 0 & & \\
\hline $\mathrm{B}_{9}$ & 0.67 & 0.67 & 0.5 & 0.67 & 0.33 & 0.5 & 0.83 & 0.33 & 0 & \\
\hline $\mathrm{B}_{10}$ & 0.63 & 0.63 & 0.5 & 0.5 & 0.33 & 00.63 & 0.75 & 0.25 & 0.38 & 0 \\
\hline
\end{tabular}

\section{Conclusion}

This paper introduces the present situation of many small and medium-sized libraries, especially the libraries in the middle schools and puts forward the existing problems and the necessity and the urgency to improve the management and to improve service quality by data mining technology. The system describes the concept, function and steps of data mining, introduces the commonly used data mining technology as correlation rules, clustering analysis and decision-making tree in detail, explains the relations between data mining and data warehouse and on-line analysis (OLAP) and designs reasonable data warehouse model and the OLAP model to fit the logical structure, network structure and database structure of the management system.

\section{Acknowledgments}

This research is supported by a grant from Humanities and Social Sciences of Hebei universities (Project Name: library embedded service innovation research of Heibei universities; Project number : SZ141266)

\section{References}

[1] Pierra, G., Poiter, J.C., Sardet, E. (2011): From digital libraries to electronic catalogues for engineering and manufacturing. International Journal of Computer Applications in Technology 18(3), 27-42

[2] Wang, P., Zhan, J. (2012): Standard Parts Library System supporting Information Sharing in Network. World Standardization \& Quality Management 10, 30-32 
[3] Pratt, M.J. (1995): Extension of STEP for the Representation of Parametric and Variational Models. In: CAD Systems Development, pp. 237-250

[4] Sardet, E., Pierra, G., Yamine, A.A. (2007): Modelling and Exchange of Classes of Components according to Plib: A case study. In Proceedings of Global Network Engineering, Antwerp, pp. 179201

[5] Sardet, E., Pierra, G. (2011): Simplified Representation of Parts Library: Model, Practice and Implementation. In: Proceedings of the 10th Product Data Technology Europe, Berkshire, UK, pp. 163-174

[6] Feng, W., Chen, J., Zhao, C. (2009): Partners Selection Process and Optimization Model for Virtual Corporations based on Genetic Algorithms. Journal of Tsinghua University (Science \& Technology) 40(10), 120-124 